This information is current as of April 26, 2023.

\title{
The Development of Subcortical Gray Matter Atrophy in Multiple Sclerosis: One Size Does Not Fit All
}

G. Pontillo, M. Petracca, S. Cocozza and A. Brunetti

AJNR Am J Neuroradiol 2020, 41 (9) E80-E81

doi: https://doi.org/10.3174/ajnr.A6698

http://www.ajnr.org/content/41/9/E80 


\section{The Development of Subcortical Gray Matter Atrophy in Multiple Sclerosis: One Size Does Not Fit All}

D eep gray matter involvement is a relevant feature of multiple sclerosis. ${ }^{1}$ Indeed, atrophy of subcortical structures, especially the thalamus, occurs in early phases and continues throughout the disease course, ${ }^{2}$ showing a strong potential for the prediction of disability ${ }^{3}$ and cognitive impairment. ${ }^{4}$

However, despite its pathophysiologic and clinical relevance, what drives this typical pattern of neurodegeneration in MS remains partially unclear, probably including a combination of primary local neuroinflammatory and neurodegenerative pathologic processes and secondary effects from remote injury in other parts of the brain (mainly white matter) via anterograde/retrograde degeneration and/or spreading of inflammation along axonal pathways. ${ }^{5}$

The study by Kalinin et al, ${ }^{6}$ published in a recent issue of the American Journal of Neuroradiology, explores the impact of purely intracortical lesions compared with white matter lesions (WMLs) on the volumes of deep gray matter structures in a cohort of patients with relapsing-remitting MS (RRMS, $n=54$ ), secondary-progressive MS (SPMS, $n=12$ ), and primary-progressive MS (PPMS, $n=5$ ). They found that patients with intracortical lesions had longer disease duration, greater disability, and more deep gray matter atrophy. WML burden was the main correlate of subcortical volume loss in patients with RRMS with a disease duration of $<5$ years and Expanded Disability Status Scale scores of $<4.0$, while a prominent impact of intracortical lesion volume on deep gray matter volumes, independent from WMLs, was found in patients with an SPMS course or longer disease duration and greater disability.

These results highlight an important point-namely that the relative weight of the different factors contributing to subcortical gray matter atrophy may vary with the disease phases and phenotypes. Indeed, if inflammation in the white matter, related to the formation of WMLs, is recognized as the major driving force for deep gray matter atrophy in early phases and a relapsing-remitting course, ${ }^{7}$ less is known about the mechanisms sustaining the enduring subcortical volume loss in chronic disease stages and a progressive course, when neuroinflammation in the white matter becomes less pronounced, as well as its impact on subcortical atrophy and disease progression. ${ }^{5}$

http://dx.doi.org/10.3174/ajnr.A6698
In this light, the correlation between cortical lesions and deep gray matter atrophy, reported by Kalinin et al, ${ }^{6}$ may reflect a second-order disconnection effect via thalamocortical radiations and corticothalamic tracts, and/or it may represent an epiphenomenon related to the prominent primary involvement of gray matter (both cortical and subcortical, simultaneously), which is known to characterize chronic disease stages and progressive phenotypes. ${ }^{1}$

Understanding the pathogenic processes underlying subcortical gray matter (primarily thalamic) atrophy in different phases of the disease would be critical in the determination of treatment strategies, potentially informing therapeutic choices with the aim of preventing the occurrence of thalamic damage and its detrimental consequences in terms of brain network economy and clinico-cognitive functioning.

To this end, recent multimodal MR imaging approaches combining the assessment of deep gray matter atrophy with the characterization of local microstructural properties, as inferred by diffusion imaging and susceptibility mapping, have yielded promising results, leading to the identification of new potential biomarkers of local pathology (eg, reduced susceptibility reflecting iron depletion in the thalamus) that may concur with, or even precede, the development of atrophy. ${ }^{7,8}$

For these reasons, we think that future longitudinal multimodal studies are strongly warranted, to unravel the causal relationship between deep gray matter atrophy and local and remote pathologic processes, as well as to understand how this complex interplay dynamically changes throughout the disease course. All along in this process, while adding pieces to the fascinating puzzle of MS pathophysiology, we should not forget John Wheeler's words of advice: "As our island of knowledge grows, so does the shore of our ignorance."

Disclosures: Maria Petracca—UNRELATED: Travel/Accommodations/Meeting Expenses Unrelated to Activities Listed: Novartis. Sirio Cocozza - UNRELATED: Board Membership: Amicus Therapeutics, Comments: Advisory Board; Payment for Lectures Including Service on Speakers Bureaus: Sanofi, Amicus Therapeutics.

\section{REFERENCES}

1. Geurts JJ, Barkhof F. Grey matter pathology in multiple sclerosis. Lancet Neurol 2008;7:841-51 CrossRef Medline

2. Azevedo CJ, Cen SY, Khadka S, et al. Thalamic atrophy in multiple sclerosis: a magnetic resonance imaging marker of neurodegeneration throughout disease. Ann Neurol 2018;83:223-34 CrossRef Medline 
3. Eshaghi A, Prados F, Brownlee WJ, et al; MAGNIMS study group. Deep gray matter volume loss drives disability worsening in multiple sclerosis. Ann Neurol 2018;83:210-22 CrossRef Medline

4. Eijlers AJC, van Geest Q, Dekker I, et al. Predicting cognitive decline in multiple sclerosis: a 5-year follow-up study. Brain 2018;141:2605-18 CrossRef Medline

5. Calabrese M, Magliozzi R, Ciccarelli O, et al. Exploring the origins of grey matter damage in multiple sclerosis. Nat Rev Neurosci 2015;16: 147-58 CrossRef Medline

6. Kalinin I, Makshakov G, Evdoshenko E. The impact of intracortical lesions on volumes of subcortical structures in multiple sclerosis. AJNR Am J Neuroradiol 2020;41:804-08 CrossRef Medline

7. Pontillo G, Cocozza S, Lanzillo R, et al. Determinants of deep gray matter atrophy in multiple sclerosis: a multimodal MRI study. AJNR Am J Neuroradiol 2019;40:99-106 CrossRef Medline
8. Zivadinov R, Tavazzi E, Bergsland N, et al. Brain iron at quantitative MRI is associated with disability in multiple sclerosis. Radiology 2018;289:487-96 CrossRef Medline

(1) G. Pontillo Department of Advanced Biomedical Sciences

(D) M. Petracca Department of Neurosciences and Reproductive and Odontostomatological Sciences

(D). Cocozza

(1) A. Brunetti Department of Advanced Biomedical Sciences University "Federico II" Naples, Italy 